\title{
Tyrosine-Protein Kinase FRK
}

National Cancer Institute

\section{Source}

National Cancer Institute. Tyrosine-Protein Kinase FRK. NCI Thesaurus. Code C29586.

Tyrosine-protein kinase FRK (505 aa, $\sim 58 \mathrm{kDa}$ ) is encoded by the human FRK gene. This protein plays a role in tyrosine phosphorylation and the negative regulation of cell proliferation. 